\title{
PENGARUH INTENSITAS MORAL DAN ETIKA PERSEPSIAN TERHADAP INTENSI KEPERILAKUAN TERKAIT SISTEM INFORMASI AKUNTANSI PADA PT. PUPUK ISKANDAR MUDA ACEH UTARA
}

\author{
Amru Usman ${ }^{1}$, Hildayatun Nufus ${ }^{2}$ \\ ${ }^{1,2}$ Prodi Akuntansi Fakultas Ekonomi dan Bisnis Universitas Malikussaleh Lhokseumawe \\ amruusman@unimal.ac.id
}

\begin{abstract}
This study aims to know the effect of moral intensity and perceived ethics on behavioral intentions related to accounting information system at PT. Pupuk Iskandar Muda, Aceh Utara. Sampling technique used census sampling where all the population used as the samples so that the samlpe in this study is 30. This study uses multiple linear regression analysis whit hypotesis testing using SPSS 16 for windows to analyze the data of this study. The results show that Moral intensity has a significant effect on behavioral intention relation to the accounting informasion system, Perceived ethical variables has a significant effect on behavioral intention related to information system.
\end{abstract}

Keywords: Perceived Ethics, Moral aintensity, Perceived Ethics, Information system.

\section{PENDAHULUAN}

Teknologi informasi merupakan suatu sarana bagi manajemen dalam mengelola bisnis dan membuat keputusan demi tercapainya tujuan perusahaan. Setiap perusahaan tentunya memiliki sistem informasi yang dapat mendukung proses bisnisnya. Sistem informasi merupakan suatu sistem pendukung operasi yang mengolah transaksi dalam organisasi dimana dari sistem tersebut nantinya akan dihasilkan laporanlaporan yang berisi informasi yang akan didistribusikan kepada para penggunanya (Leitch dan Davis, dalam Hartono, 2009:11).

Salah satu sistem informasi yang ada dalam perusahaan adalah sistem informasi akuntansi, yaitu merupakan bagian dari sistem informasi manajemen yang mengolah data akuntansi dari aktivitas rutin sehingga menghasilkan informasi akuntansi dimana informasi tersebut akan didistribusikan ke para penggunanya untuk mendukung pengambilan keputusan pengguna sistem informasi akuntansi dan memunculkan berbagai isu etikaIsu-isu etika yang terjadi di berbagai lingkungan bisnis semakin bergejolak dikarenakan oleh semakin ketatnya persaingan di dunia bisnis, yang menuntut perusahaan untuk mempertahankan bisnis yang dijalankannya dan tentunya mengembangkan bisnis tersebut. Setiap perusahaan memiliki tujuan untuk selalu berkembang dan perkembangan tersebut tidak lepas dari peran akuntan internal dalam menjalankan fungsinya guna memenuhi kebutuhan informasi akuntansi bagi berbagai pihak. Etika merupakan hal yang mendasari individu dalam membuat pilihan untuk bertindak etis atau tidak dalam suatu situasi etis (Hall, 2009:149).

Fenomena yang terjadi di PT. Pupuk Iskandar Muda Aceh Utara yaitu pada november 2017 terhentinyaproduksipupuk urea dan amonia yang mengakibatkan terhentinya seluruh operasional di PT. PIM .Begitu pula dengan system informasia kuntansi yang juga ikut terhenti selama 6 bulanlamanya. Pada saatitu Manager tidak bias mengatasi hal tersebut yang mengakibatkan target awal menjadi tidak tercapai. Dan hal ini menjadikan manager tidak bias mengambil keputusan yang tepat sesuai dengan etika persepsian sebagai manager.

\section{TINJAUAN PUSTAKA}

Intensi Keperilakuan

Intensi Keperilakuan didefinisikan sebagai suatu keinginan individu untuk melakukan atau tidak melakukan perilaku yaitu keinginan untuk berperilaku etis atau tidak etis (Ajzen 1991). Sedangkan menurut Fishbein (1975) dalam Davis et al. (1989), Intensi Keperilakuan didefinisikan sebagai sebuah ukuran dari kekuatan sebuah keinginan untuk melakukan suatu perilaku yang spesifik. perilaku pengambilan keputusan dikembangkan di luar jalur teoridan penelitian perilaku organisasi oleh psikolog kognitif dan ahli teori keputusandalam ilmu ekonomi dan informasi. Akan tetapi, barubaru ini muncul 
kembaliminat mengenai perilaku pengambilan keputusan, dan kembali ke jalur bidangperilaku organisasi. (Robbins, 2008)

Meskipun teori pengambilan keputusan klasik berjalan dalam asumsirasionalitas dan kepastian, tetapi tidak begitu halnya dengan teori keputusan perilaku. Ahli teori perilaku pengambilan keputusan sependapat bahwa individu mempunyai keterbatasan kognitif. Kompleksitas organisasi dan dunia secara umum menyebabkan individu bertindak dalam situasi ketidakpastian daninformasi begitu arnbigu dan tidak lengkap. Kadang-kadang risiko dan ketidakpastian ini menyebabkan pembuat keputusan organisasi mempunyaikeputusan yang diragukan, atau tidak etis. Dikarenakan ketidakpastian dan ambiguitas, sejumlah model pengambilan keputusan telah ada selama bertahuntahun.Dasar dan titik awal untuk mengembangkan menganalisis berbagai modelperilaku pengambilan keputusan adalah tetap mempertahankan tingkat dan arti rasionalitas. (Robbins, 2008)

\section{Intensitas Moral}

Jones (1991) mengajukan sebuah konstruk yang terkait dengan isu-isu moral yang dikenal dengan Intensitas Moral. Intensitas Moral adalah sebuah konstruk yang mencakup karakteristik-karakteristik yang merupakan perluasan dari isu-isu yang terkait dengan imperatif moral dalam sebuah situasi. Intensitas Moral bersifat multidimensi, dan komponenkomponen bagiannya merupakan karakteristik dari isu-isu moral.

Jones (1991) komponen-komponen dari karakteristik-karakteristik tersebut yaitu: (1) besaran konsekuensi (the magnitude of consequences), didefinisikan sebagai jumlah kerugian (atau manfaat) yang dihasilkan oleh pengorbanan (atau kebermanfaatan) dari sebuah tindakan moral; (2) konsensus sosial (social consensus) didefinisikan sebagai tingkat kesepakatan sosial bahwa sebuah tindakan dianggap jahat atau baik; (3) probabilitas efek (probability of effect) merupakan sebuah fungsi bersama dari kemungkinan bahwa tindakan tertentu akan secara aktual mengambil tempat dan tindakan tersebut akan secara aktual menyebabkan kerugian (manfaat) yang terprediksi; (4) kesegeraan temporal (temporal immediacy) adalah jarak atau waktu antara pada saat terjadi dan awal mula konsekuensi dari sebuah tindakan moral tertentu (waktu yang makin pendek menunjukkan kesiapan yang lebih besar); (5) kedekatan (proximity) adalah perasaan kedekatan (sosial, budaya, psikologi, atau fisik) yang dimiliki oleh pembawa moral (moral agent) untuk si pelaku dari kejahatan (kemanfaatan) dari suatu tindakan tertentu; (6) konsentrasi efek (concentration of effect) adalah sebuah fungsi infers dari jumlah orang yang mempengaruhi dan dipengaruhi oleh sebuah tindakan yang dilakukan.

Intensitas Moral tidak memasukkan karakter dari pembuat keputusan, misalnya seperti perkembangan moral (Trevino, 1986); atau pengetahuan maupun nilai (Ferrel \& Gresham, 1985), juga tidak mempertimbangkan faktor-faktor organisasi, seperti budaya organisasi (Trevino, 1986) maupun kebijakan perusahaan (Ferrel \& Gresham, 1985). Intensitas Moral fokus pada isu moral, bukan pada pembawa moral (moral agent) maupun konteks organisasi.

\section{Etika Persepsian}

Norma-norma individu dilekatkan dalam konsep-konsep pribadi individu yang didasarkan pada kepercayaan dan sistem nilai yang dianut. Pemahaman norma-norma sosial membutuhkan penyesuaian nilai-nilai yang secara intrinsik menuntun perilaku dan menentukan jika perilaku pengaruhan diterima atau ditolak (Malhotra \& Galleta, 2005). Masalah Etika Persepsian adalah suatu pandangan bagaimana seorang individu memandang dan menilai suatu situasi apakah termasuk ke dalam masalah etis atau tidak (Goles et al., 2006).

Masalah Etika Persepsian yang dimiliki individu merupakan hasil dari pemahaman norma-norma sosial. Setelah seorang individu melakukan penilaian terhadap karakteristikkarakteristik dari isu moral dan memiliki persepsi terhadap sebuah situasi etis maka akan mempengaruhi perilakunya kemudian (Goles et al., 2006) sehingga peneliti mengajukan hubungan positif antara persepsi sebuah masalah etika dan keinginan untuk berperilaku secara etis.

Etikaberasaldari kata ethos sebuah kata dari Yunani, yang diartikanidentikdengan moral ataumoralitas. Keduaistilahinidijadikansebagaipedomanatauuku ranbagitindakanmanusiadenganpenilaianbaikatau buruk dan beneratau salah (Syukry dan Halim : 2002).

Etikamelibatkananalisiskritismengenaiti ndakanmanusiauntukmenentukansuatunilaibenar dan salah darisegikebenaran dan keadilan. Jadiukuran yang dipergunakanadalahnorma, agama, nilaipositif dan unversalitas. Oleh karenaitu, istilahetikaseringdikonotasikandenganistilahistilah: tata krama, sopansantun, pedoman moral, normasusila, dan lain-lain yang berpijak pada norma-norma tata hubunganantarunsuratauantarelemendidalammas yarakat dan lingkungannya (Lubis : 2010). 


\section{Sistem Informasi Akuntansi}

Pada perusahaan yang masih kecil skala operasinya, pimpinan perusahaan masih dapat langsung terjun ke dalam setiap bagian pekerjaan sehingga ia dapat langsung mengetahui dan mengawasi keadaan perusahaan. Dalam situasi ini, fungsi akuntansi hanya diselenggarakan secara informal saja atau diselenggarakan sebagai bagian dari fungsi yang lain atau sama sekali diabaikan dan diselenggarakan sekali setahun pada saat informasi untuk tujuan fiskal diperlukan. Hal ini disebabkan karena kedudukan manajer dan pemilik terdiri dari satu atau beberapa orang saja serta terbatasnya jumlah karyawan, dan pengelolaan dan supervisi dilakukan secara langsung dan pribadi, maka informai akuntansi belum dirasakan manfaatnya.

\section{Penelitian Terdahulu}

Dalam melakukan penelitian ini penulis mengacu kepada beberapa beberapa penelitian terdahulu, yang berkaitan dengan penelitian ini :

1. Mianingsih (2009)
Melakukan penelitian tentang Analisis Pengaruh Intensitas Moral Terhadap Intensi Keperilakuan: Peranan Masalah Etika Persepsian Dalam Pengambilan Keputusan Etis Yang Terkait Dengan Sistem Informasi Akuntansi.

Hasil penelitian menunjukkan etika persepsian dan intensitas moral memiliki pengaruh signifikansinya terhadap intensi perilaku untuk membuat etis keputusan yang berkaitan dengan sistem informasi akuntansi.

2. Dwijayanti (2009)

Melakukan penelitian tentang Pengaruh Kecerdasan Emosional, Kecerdasan Intelektual, Kecerdasan Spiritual dan Kecerdasan Sosial terhadap Pemahaman Akuntansi.

Hasil penelitian menunnjukkan kecerdasan emosional dan kecerdasan spiritual tidak berpengaruh terhadap pemahaman akuntansi.

\section{.Kerangka Konseptual \\ Variabel dependen dalam penelitian ini adalah intensi keperilakuan , sedangkanvariabelindependennyaadalahintensitas moral dan etika persepsian.}

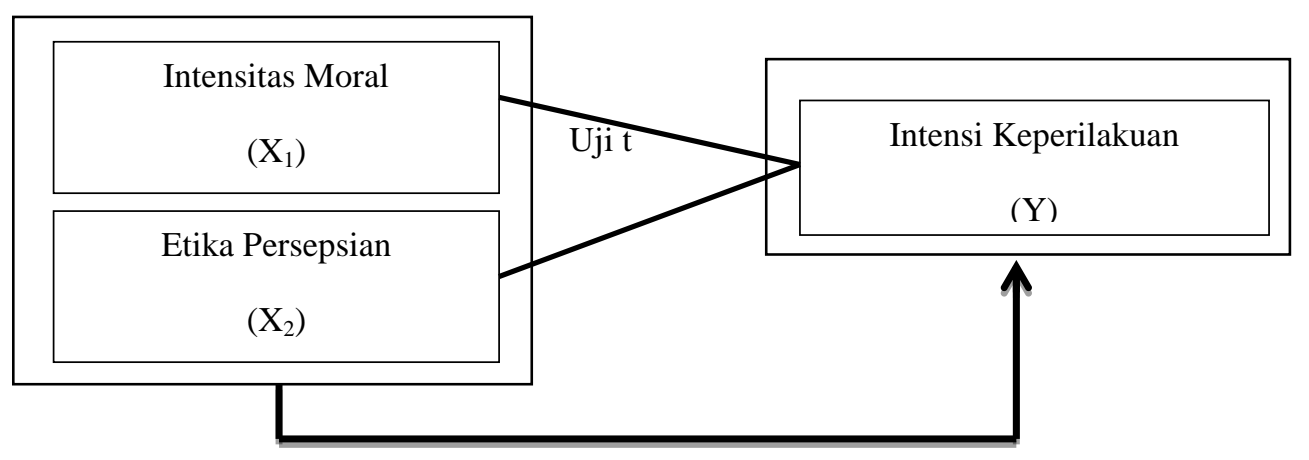

\section{Gambar1.KerangkaKonseptual}

\section{METODOLOGI PENELITIAN}

\section{Objek dan Lokasi Penelitian}

Penelitian ini akan menguji Pengaruh Intensitas Moral Dan Etika Persepsian Terhadap Intensi Keperilakuan Terkait Sistem Informasi Akuntansi Pada PT. Pupuk Iskandar Muda Aceh Utara ( Jl. Medan-Banda Aceh PO. Box 021 Krueng Geukuh, Aceh Utara).

\section{Populasi dan Sampel}

Populasi adalah wilayah generalisasi yang terdiri atas obyek atau subyek yang mempunyai kuantitas dan karakteristik tertentu yang ditetapkan oleh peneliti untuk dipelajari dan kemudian ditarik kesimpulan (Sugiyono, 2006:55). Populasi pada penelitian ini adalah lower manajer dan staf bagian akuntansi PT. Pupuk Iskandar Muda Aceh Utara.Jumlahpopulasidalampenelitianini42.

Sedangkansampel merupakan sebagian atau wakil dari populasi yang diteliti. Arikunto (2013:174). Teknik pengambilansampel yang digunakandalampenelitianiniadalah probability sampling. Karakteristik yang menjadisampeldalampenelitianiniadalah lower manajer dan staf bagian akuntasi PT. Pupuk Iskandar Muda Aceh Utara. Dalam penelitian ini 
menggunakan sensus jenuh dimana populasi dan sampel dipakai semua.

\section{Teknik Pengumpulan Data}

Penelitian ini menggunakan data primer dengan metode yang digunakan untuk memperoleh data adalah metode dokumentasi dan metode survei, dengan menggunakan teknik kuisioner yang

merupakan daftar pertanyaan terstruktur yang ditujukan kepada sampel.

\section{Metode Analisis Data}

Analisis regresi linear berganda digunakan untuk menaksir bagaimana keadaan (naik turunnya) variabel dependen, bila dua atau lebih variabel dependen sebagai faktor predictor dimanipulasi (dinaik turunkan nilainya). Maka digunakan alat analisis regresi linier berganda dengan formulasi sebagai berikut :

$\begin{array}{ll} & \mathbf{Y}=\mathbf{a}+\mathbf{b} 1 \mathbf{X} 1+\mathbf{b} 2 \mathbf{X} 2+\mathbf{e} \\ \text { Keterangan: } & \\ \mathrm{Y} & \text { : KepuasanPenggunaSistem } \\ & \text { E-Kinerja } \\ \text { a } & \text { : Konstanta } \\ \mathrm{X} 1 & \text { :Kapabilitas Personal }\end{array}$

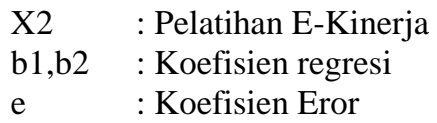

\section{HASIL PENELITIAN DAN PEMBAHASAN}

\section{Uji Validitas}

Uji validitas digunakan untuk mengukur sah atau valid tidaknya suatu kuesioner. Suatu kuesioner dikatakan valid jika pertanyaan pada kuesioner mampu untuk mengungkapkan sesuatu yang akan diukur oleh kuesioner tersebut. Menurut Ghozali (2006), validitas data dapat diukur dengan membandingkan $r_{\text {hitung }}$ dengan $r_{\text {tabel }}$ (r product moment), dimana jika: (1). Jika $\mathrm{r}_{\text {hasil }}$ positif serta $r_{\text {hasil }}>r_{\text {tabel }}$, maka butir atau variabel tersebut valid; (2). Jika $r_{\text {hasil }}$ tidak positif serta rhasil $<r_{\text {tabel }}$, maka butir atau variabel tersebut tidak valid. Jadi rhasil untuk tiap item bisa dilihat pada kolom corrected item-total correlation, dan untuk degree of freedom $(\mathrm{df})=\mathrm{n}-2$, dimana $\mathrm{n}$ adalah jumlah sampel (Ghozali, 2006), berarti df $=94-2=92$, dengan tingkat signifikansi $5 \%$ didapat angka pada $r$ tabel $=0,171$ (uji dua sisi). Untuk lebih jelas dapat dilihat pada tabelberikut ini:

Tabel 1 Hasil PengujianValiditas

\begin{tabular}{|c|c|c|c|c|}
\hline No & Butir Pertanyaan & $\begin{array}{l}\text { corrected item-total } \\
\text { correlation }\end{array}$ & $\mathrm{R}$ tabel & Keterangan \\
\hline 1 & $\begin{array}{cc}\text { Intensitas } & \text { Moral }(\mathrm{X} 1) \\
\begin{array}{cc}\text { a. } & \mathrm{X}_{1} \mathrm{Q}_{1} \\
\text { b. } & \mathrm{X}_{1} \mathrm{Q}_{2} \\
\text { c. } & \mathrm{X}_{1} \mathrm{Q}_{3} \\
\text { d. } & \mathrm{X}_{1} \mathrm{Q}_{4} \\
\text { e. } & \mathrm{X}_{1} \mathrm{Q}_{5} \\
\text { f. } & \mathrm{X}_{1} \mathrm{Q}_{6} \\
\text { g. } & \mathrm{X}_{1} \mathrm{Q}_{7} \\
\text { h. } & \mathrm{X}_{1} \mathrm{Q}_{8}\end{array}\end{array}$ & $\begin{array}{l}0,721 \\
0,588 \\
0,739 \\
0,601 \\
0,602 \\
0,498 \\
0,388 \\
0,721\end{array}$ & 0,361 & Valid \\
\hline 2 & $\begin{array}{cc}\text { Etika } & \text { Persepsian }\left(\mathrm{X}_{2}\right) \\
\begin{array}{cc}\text { a. } & \mathrm{X}_{2} \mathrm{Q}_{1} \\
\text { b. } & \mathrm{X}_{2} \mathrm{Q}_{2} \\
\text { c. } & \mathrm{X}_{2} \mathrm{Q}_{3} \\
\text { d. } & \mathrm{X}_{2} \mathrm{Q}_{4} \\
\text { e. } & \mathrm{X}_{2} \mathrm{Q}_{5} \\
\text { f. } & \mathrm{X}_{2} \mathrm{Q}_{6} \\
\text { g. } & \mathrm{X}_{2} \mathrm{Q}_{7} \\
\text { h. } & \mathrm{X}_{2} \mathrm{Q}_{8} \\
\end{array}\end{array}$ & $\begin{array}{l}0,374 \\
0,526 \\
0,389 \\
0,526 \\
0,370 \\
0,592 \\
0,511 \\
0,526 \\
\end{array}$ & 0,361 & Valid \\
\hline 3 & Intensi Keprilakuan & & 0,361 & Valid \\
\hline
\end{tabular}


Volume 5, Nomor 2, Agustus 2017

\begin{tabular}{|c|c|c|l|l|}
\hline Terkait & SIA(Y) & 0,519 & & \\
a. $\mathrm{YQ}_{1}$ & 0,474 & & \\
b. $\mathrm{YQ}_{2}$ & 0,724 & & \\
c. $\mathrm{YQ}_{3}$ & 0,767 & & \\
d. $\mathrm{YQ}_{4}$ & 0,453 & & \\
e. $\mathrm{YQ}_{5}$ & 0,573 & & \\
f. $\mathrm{YQ}_{6}$ & 0,374 & & \\
g. $\mathrm{YQ}_{7}$ & 0,427 & & \\
h. $\mathrm{YQ}_{8}$ & & & \\
\end{tabular}

Sumber: diolah peneliti, 2018

Berdasarkan Tabel 4.4 di atas, terlihat bahwa dari 24 (dua puluh empat) butir pertanyaan, semua mempunyai $r_{\text {hasil }}$ di atas $r_{\text {tabel }}$ (0,361). Hasil uji validitas menunjukkan bahwa seluruh butir pertanyaan angket pada 2variabel independen danvariabeldependendinyatakan valid. Butir pertanyaan dikatakan valid karena rhitung> rtabel dengan nilai signifikan setiap pertanyaan 5\%. Hal ini menunjukkan bahwa masing-masing pertanyaan angket sahih dan dapat dipercaya untuk mengambil data penelitian.

\section{Uji Reliabilitas}

Uji reliabilitas digunakan untuk mengukur suatu kuesioner yang merupakan indikator dari variabel atau kontruk. Suatu kuesioner dikatakan reliabel jika jawaban seseorang terhadap pertanyaan adalah konsisten atau stabil.Pengujian reliabilitas dalam penelitian ini adalah dengan menggunakan rumus alpha. Menurut Ghozali (2013: 47), adalah: (1). Jika nilai hasil croanbach alpha> 0,60, maka butir atau variabel tersebut reliabel; (2). Jika nilai hasil croanbach alpha< 0,60, maka butir atau variabel tersebut tidak reliabel.Berikut ini adalah tabel hasil pengujian reliabilitas:

Tabel 2 Hasil Pengujian Reliabilitas

\begin{tabular}{|l|c|c|c|}
\hline \multicolumn{1}{|c|}{ Variabel } & Alpha & Batasan & Keterangan \\
\hline Intensitas Moral $\left(\mathrm{X}_{1}\right)$ & 0,775 & 0,60 & Reliabel \\
\hline Etika Persepsian $\left(\mathrm{X}_{2}\right)$ & 0,882 & 0,60 & Reliabel \\
\hline Intensi Keprilakukan Terkait SIA $(\mathrm{Z})$ & 0,664 & 0,60 & Reliabel \\
\hline
\end{tabular}

Sumber: diolah peneliti, 2018

Berdasarkan Tabel 4.5 di atas terlihat bahwa hasil croanbach alpha dari variabel Intensitas $\operatorname{Moral}\left(\mathrm{X}_{1}\right)$ yaitu sebesar $0,775>0,60$, Etika persepsian $\left(\mathrm{X}_{2}\right)$ sebesar $0,882>0,60$, dan Intensi keprilakuan tekait SIA(Y) sebesar0,664>0,60. Dengan demikian semua butir-butir variabel pertanyaan di atas adalah reliabel

Gambar 2 Normal P-P Plot Of Regression Standardized Residual.

Berdasarkan Gambar 2 grafik normal plot, menunjukkan bahwa model regresi layak dipakai dalam penelitian ini karena grafik normal plot terlihat titik-titik menyebar disekitar garis diagonal serta penyebaran mengikuti arah garis diagonal menunjukkan pola distribusi normal,

Berdasarkan tabel diatas terlihatbahwa asymp.sig. (2-tailed) sebesar 0,757 artinya asmp.sig. (2-tailed) >0,05 $(0,757>0,05)$ sehingga dapat disimpulka data berdistribusi normal dan terbesar dari uji normalitas.

\section{Uji Asumsi Klasik}

Uji Normalitas

Uji normalitas bertujuan untuk menguji variabel independen dan variabel dependen keduanya memiliki distribusi normal atau tidak.

sehingga model regresi memenuhi asumsi normalitas.Selainituuntukmengujinormalitas juga diujidenganmenggunakan one-sample kolmogorovsmirnov test dimanajikaAsmp.sig. (2 Tailed) > $\quad 0,05$ dikatakanbahwapenelitianterbesasdari uji normalitas dan demikian juga sebaliknya. Pengujiandengan one sample kolmogorvsmirnovdapatdilihat pada tabeldibawa

\section{Uji Multikolienaritas}


Untuk menguji apakah terdapat interkorelasi yang sempurna diantara beberapa variabel bebas digunakan dalam persamaan regresi digunakan uji multikolinieritas. Uji multikoliniertas menggunakan nilai tolerance dan VIF (varian inflation factor). Berdasarkan hasil perhitungan dengan SPSS versi 17.0 didapatkan hasilsebagaiberikut:

Tabel 4. Hasil Pengujian Multikolinieritas

\begin{tabular}{|l|l|l|l|}
\hline \multirow{2}{*}{ Variabel } & \multicolumn{2}{|c|}{ Collinearity Statistic } & \multirow{2}{*}{ Keterangan } \\
\cline { 2 - 3 } & \multicolumn{1}{|c|}{ Tolerance } & \multicolumn{1}{|c|}{ VIF } & \\
\hline $\mathrm{X}_{1}$ & 0,753 & 1,329 & Tidak ada multikolinearitas \\
$\mathrm{X}_{2}$ & 0,753 & 1,329 & Tidak ada multikolinearitas \\
\hline
\end{tabular}

Sumber: Data Primer, 2018 (diolah)

Dari Tabel 4 di atas terlihat bahwa nilai tolerance dan nilai VIF menunjukkan tidak ada satu variabel yang memiliki nilai VIF lebih dari 10 dan nilai tolerance juga menunjukkan tidak satu variabel bebas yang memiliki nilai tolerance kurang dari $10 \%$. Dan ini berarti tidak ada korelasi antar variabel bebas yang nilainya lebih dari $90 \%$. Hasil itu menandakan bahwa model regresi yang dihasilkan tidak terjadi multikolinieritas.

\section{Analisis Regresi Linier Berganda}

Berdasarkan dari hasil uji analisis regresi linier berganda dengan alat bantu komputer yang menggunakan program SPSS versi 17, dapat dilihat pada tabel 4 sebagai berikut :

Tabel 5.Hasil AnalisisRegresi Linear Berganda

Coefficients $^{\mathrm{a}}$

\begin{tabular}{|l|r|r|r|r|r|}
\hline \multirow{2}{*}{ Model } & \multicolumn{2}{|c|}{$\begin{array}{c}\text { Unstandardized } \\
\text { Coefficients }\end{array}$} & \multicolumn{1}{c|}{$\begin{array}{c}\text { Standardized } \\
\text { Coefficients }\end{array}$} & & \\
\cline { 2 - 4 } & \multicolumn{1}{|c|}{$\mathrm{B}$} & Std. Error & \multicolumn{1}{|c|}{ Beta } & \multicolumn{1}{c|}{$\mathrm{T}$} & \multicolumn{1}{c|}{ Sig. } \\
\hline $1 \quad$ (Constant) & 1.963 & 4.191 & & .468 & .643 \\
X2 & .318 & .121 & .320 & 2.631 & .014 \\
X1 & .635 & .123 & .629 & 5.166 & .000 \\
\hline
\end{tabular}

a. Dependent Variable: Y

Sumber: Data Primer, 2018

Dari hasil regresi yang didapat maka dapat dibuat persamaaan regresi sebagai berikut : $\mathrm{Y} 1=1,963+0,318 \mathrm{X} 1+0,635 \mathrm{X} 2+\mathrm{e}$

Persamaan regresi tersebut mempunyai arti sebagai berikut:

1. Nilai konstanta (a) adalah 1,963, dapat diartikan jika Intensitas moral dan etika persepsian nilainya 0 (nol), maka intensi keprilakuan terkait sistem informasi akuntansi adalah sebesar 1,963 satuan.

2. Nilai koofisien regresi variabel intensitas moral $\left(b_{1}\right)$ bernilai positif, yaitu 0,318 , maka dapat diartikan bahwa setiap peningkatan intensitassebesar $1 \%$ maka akan menaikkan intensi keprilakuan terkait sistem informasi akuntansi sebesar $31,8 \%$ dengan asumsi variabel independen lainnya tetap.
3. Nilai koofisien regresi variabel etika persepsian $\left(b_{2}\right)$ bernilai positif yaitu sebesar 0,635, maka dapat diartikan bahwa setiap peningkatan etika persepsian sebesar $1 \%$ maka akan menaikkaan tingkat intensi keprilakuan terkait sistem informasi akuntansi sebesar 63,5\% dengan asumsi variabel independen lainnya tetap.

\section{Uji Parsial (Uji t)}

Uji - $\mathrm{t}$ ini digunakan untuk membuktikan pengaruh yang signifikan antaravariabel independen terhadap variabel dependen, dimana apabila nilai $\mathrm{t}$ hitung lebih besar dari $t$ tabel menunjukkan diterimanya hipotesis yang diajukan. Nilai $\mathrm{t}$ hitung dapat dilihat pada hasil regresi dan nilai t tabel didapat melalui sig. $\alpha=0,05$ dengan $\mathrm{df}=\mathrm{n}-\mathrm{k}$ 
1. Pengaruh intensitas moral Terhadap intensi keprilakuan terkait sistem infromasi akuntansi.

Berdasarkan perhitungan statistik pada tabel 4.8 diatas diperoleh $\mathrm{t}$ hitung sebesar 2,631 dan t tabel sebesar 2,048 diperoleh dari $\mathrm{df}=\mathrm{n}-\mathrm{k} \quad(30-2=28)$ dengan taraf sig. 0,05 sehingga dapat disimpulkan bahwa thitung > ttabel $(2,631>2,048)$ maka H1 diterima dan H0 ditolak. Artinya intensitas moral berpengaruh terhadap intensi keprilakuan terkait sistem akuntansi.
2. Pengaruh etika persepsianterhadap intensi keprilakuan terkait sistem akuntansi.

Berdasarkan perhitungan statistik pada tabel 4.8 diatas diperoleh $\mathrm{t}$ hitung sebesar 5,166 dan $\mathrm{t}$ tabel sebesar 2,048 diperoleh dari $\mathrm{df}=\mathrm{n}-\mathrm{k}$ $(30-2=28)$ dengan taraf sig. 0,05 sehingga dapat disimpulkan bahwa thitung $>$ ttabel $(5,166>$ 2,048) maka H2 diterima dan H0 ditolak. Artinya etika persepsian berpengaruh terhadap intensi keprilakuan terkait sistem akuntansi.

\section{Uji Simultan (Uji F)}

Uji F

dilakukanadalahuntukmengetahuipengaruhvariab elindependenterhadap variabel dependen secara simultan. Hasil uji $\mathrm{F}$ dapat dilihat pada tabel 7 berikut:

Tabel 6. Hasil Uji F

ANOVA $^{b}$

\begin{tabular}{|ll|r|r|r|r|r|}
\hline Model & & Sum of Squares & Df & Mean Square & F & Sig. \\
\hline 1 & Regression & 161.677 & 2 & 80.839 & 31.320 & $.000^{\mathrm{a}}$ \\
& Residual & 69.690 & 27 & 2.581 & & \\
& Total & 231.367 & 29 & & & \\
\hline
\end{tabular}

a. Predictors: (Constant), X1, X2

b. Dependent Variable: Y

Sumber: Data Primer, 2018 (diolah)

Berdasarkan hasil pengujian statistik menggunakan SPSS diperoleh Fhitung sebesar 31,320 dengan sig 0,000 artinya secara simultan variabel independen berpengaruh terhadap variabel dependen. Maka menerima H3 dan menolak H0 artinya secara simultan intensitas moral dan etika persepsian berpengaruh terhadap intensi keprilakuan terkait sistem informasi akuntansi.

\section{Koefisien Determinasi}

Koefisien determinasi merupakan kuadrat dari koefisien korelasi sebagai ukuran untuk mengetahui kemampuan dari masing masing variabel yang digunakan. Koefisien determinasi $\left(\mathrm{R}^{2}\right)$ mengukur seberapa jauh kemampuan model yang dibentuk dalam menerangkan variasi variabel independen. Nilai koefisien determinasi $\left(\mathrm{R}^{2}\right)$ yaitu antara nol dan satu. Nilai $R^{2}$ yang kecil mengindikasikan variabel independen memberikan hampir semua informasi yang dibutuhkan untuk dilakukannya prediksi terhadap variabel dependen (Imam Ghozali, 2011: 97).

\section{PENUTUP}

\section{Kesimpulan}

Berdasarkan hasil penelitian dan pembahasan yang telah diuraikan penulis maka penulis mengemukakan kesimpulan:

1. Hasil pengujian hipotesis diperoleh bahwa variabel intensitas moral berpengaruh signifikan terhadap intensi keprilakuan terkait sistem akuntansi pada PT. Pupuk iskandar muda aceh utara. Hasil ini menunjukkan bahwa Intensitas moral yang baik dapat 
membuat karyawan lebik efektif dalam melakukan pekerjaan nya terkait sistem informasi akuntansi.

2. Hasil pengujian hipotesi kedua diperoleh bahwa variabel etika persepsian berpengaruh signifikan terhadap intensi keprilakuan terkait sistem akuntansi pada PT. Pupuk iskandar muda aceh utara. Hasil ini menunjukkan etika persepsian yang baik bisa membuat manejer ataupun karyawan lebih bertidak adil dalam membuat suatu keputusan yang terkait sistem informasi akuntansi.

3.

4. Pengujian hipotesis dengan uji $F$ dilakukan dengan membandingkan antara $F_{\text {hitung }}$ dengan $F_{\text {tabel }}$, dan nilai signifikansinya menunjukkan bahwa secara simultan intensitas moral dan etika persepsian berpengaruh signifikan terhadap intensi keprilakuan terkait sistem informasi akuntansi pada PT. Pupuk iskandar muda aceh utara. Dengan adanya intensitas moral dan etika persepsian yang baik maka akan membuat intensi keperilakuan lebih baik dalam melakukan pekerjaan ataupun membuat keputusan yang terkait sistem informasi akuntansi pada PT. Pupuk Iskandar Muda aceh utara.

\section{KeterbatasanPenelitian}

Penelitian ini memiliki beberapa keterbatasan yang dapat mempengaruhi hasil penelitian. Keterbatasan hasil penelitian tersebut antara lain

1. Periode waktu yang digunakan dalam penelitian hanya 1 tahun yaitu tahun 2017.

2. Dalam penelitian ini terbatasnya hanya menggunakan 2 variabel yang masih sangat lemah dalam menilai intensi keperilakuan terkait sistem informasi akuntansi dan masih banyak faktor-faktor lain yang dapat digunakan dalam menentukan intensi keperilakuan tersebut.

Saran

telahdilakukan,

Berdasarkanhasilpenelitian yang

makapenilitimemberikanbeberapa saran

sebagaiberikut:

1. Periode penelitian selanjutnya sebaiknya lebih dari 2 tahun karena periode yang lebih panjang diharapkan dapat memungkinkan tingkat kebenaran 100\% sehingga mencerminkan kondisi perusahaan yang sebenarnya.

2. Penelitian selanjutnya diharapkan dapat menambahkan variabel lain sehingga dapat diketahui banyak hal yang dapat mempengaruhi intensi keperilakuan terkait sistem informasi akuntansi.

3. Kepada manajer ataupun karyawan agar lebih efektif dan efisien dalam mengambil sebuah keputusan terkait sistem informasi akuntansi agar dapat memperoleh tujuan perusahaan.

\section{KEPUSTAKAAN}

ArfanIkhsanLubis.

(2010).AkuntansiKeperilakuan.Jakarta :SalembaEmpat.

Ajzen. (1991). Organizational Behavior And Human Decision Processes.

Bungin, M, Burhan. (2008). Penelitian Kualitatif. Jakarta, Kencana Pranada Media Grup

Dewi dan Godono. (2007). "Analisis Pengaruh Intensitas Moral Terhadap Intensi Keperilakukan:Peranan Masalah Etika Persepsiandalam Pengambilan Keputusan Etis YangTerkait Dengan Sistem Informasi”. Simposium Nasional Akuntansi X, UnhasMakasar.

Dwijayanti. (2009). Pengaruh Kecerdasan Emosional, Kecerdasan Intelektual, Kecerdasan Spiritual Dan Kecerdasan Sosial Terhadap Pemahaman Akuntansi. Skripsi. Universitas Pembangunan Nasional. "VETERAN". Jakarta.

Fajar Prakosa. (2010). Pengaruh Intensitas Moral Terhadap Etika Pengambilan Keputusan Pengguna Sistem Informasi. Universitas Budi Luhur.

Goles, T., Gregory B, Nocole B, Carloss A,Barbara, H. (2006). "Moral Intensity Andethical DecisionMaking: A Contextualextension". The Data Base For AdvancesIn Information Systems - Spring-Summer Vol. 37, Nos. 2 \& 3, Pp. 86-95

Ghozzali, Imam. (2013). Aplikasi Analisis Multivariate Dengan Program Spss Edisi Ketujuh. Semarang, Badan Penerbit Universitas Diponegoro. 
Volume 5, Nomor 2, Agustus 2017

Hadi, Sutrisno. (2004). Metodologi Research Jilid 3, Yogyakarta.

Hall. (2009). https://dwiermayanti.wordpress.com/ 2009/10/13/sistem-informasiakuntansi/. Diunduh pada 1 maret 2018

Indrianto, Nur dan Bambang, Supomo. (2011) Metodologi Penelitian Bisnis Untuk Akuntansi Dan Manajemen, Edisi Pertama. BPFE, Yogyakarta.

Johari. (2008). Bionics by Examples: 250 Scenarios from Classical to Modern Times. 
